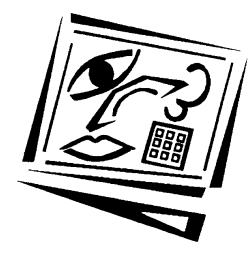

\title{
Managing change: The use of mixed delivery modes to increase learning opportunities
}

\author{
Sue Franklin and Mary Peat \\ Biological Sciences, The University of Sydney
}

\begin{abstract}
Science teaching in the new millennium will need to suit the students' needs and understanding, and employers' expectations. Choosing to learn will help form the learning opportunities presented. This paper looks at the way the delivery of teaching and learning materials for large first year biology units of study has changed over a period of time during which there have been reductions in staff resources and increases in student numbers. The strategies currently used to manage student learning and improve the learning experience will be detailed. These include a mix of on campus and online opportunities such as the management of laboratory classes in a peer mode model and the recent re-purposing of existing online resources to provide a Virtual Learning Environment (VLE). The VLE offers a safe, student centred learning environment with access to synchronous and asynchronous communications, and access to learning and assessment materials. Reasons for the development of the VLE are discussed, with ideas on the management of campus based teaching in the experimental sciences.
\end{abstract}

\section{Introduction}

Universities today are in transition. Much of the change we see is driven by economic pressures and demands for graduates who will be able to function in a knowledge society. To cope with these pressures and demands, the majority of universities are turning to the use of the Internet and intranets to deliver courses at distance as well as to enhance on campus educational programs. Information technology (IT) has the potential to solve many of the problems associated with these societal pressures and the concurrent changes in the higher education sector (costs, quality of materials, focus on customer needs, response to competitive pressures). IT can change the roles of students and teachers, facilitate more 
student centred learning and expand the scope and content of the curriculum (Horgan, 1998). The concept of lifelong learning and its merging with post-tertiary work is a reality and education needs to take on a more societal based outlook to provide for these demands. New models to address issues such as increased student mobility and choice, the merging of work and learning, and ubiquitous, affordable communication systems must be developed.

There are important issues confronting academics teaching in large first year science courses, such as student retention and progression, equity of access to resources as well as the changing needs of incoming students. Many of these issues arise from the increasing number and diversity of students, concurrent with the reduction in recurrent resources. We are all struggling with a reduction in tenured staff and an increase in casual teaching in first year, along with the added pressure to increase research output. For many staff, working with first year students is now seen to be a less valuable activity than supporting the learning environments of higher year students (which yield honours and postgraduate candidates), as previously recognised by Christopoulos, Rohwer \& Thomas (1987).

The ability of many students to attend campus is often compromised by their need to seek paid employment (McInnis, James \& McNaught, 1995). Students juggle university commitments with employment, potentially missing some of the structured teaching and learning sessions and, more importantly, not being able to take advantage of campus based course materials and face to face assistance from staff. Part time work makes it extremely difficult for some students to fulfil course expectations (McInnis, James \& McNaught, 1995). Demographic data from over 700 first year biology students at the University of Sydney show that students are not only taking a full time university load but are working long hours in paid work (Peat \& Franklin, 2000). These surveys show that since 1998 both the percentage of students in work and the number of hours worked has increased. In 1998, 48\% of students undertook casual work during the semester and worked on average 5-10 hours per week, whilst in 2000 the number of students in casual paid work had increased to $67 \%$, averaging from 5-15 hours per week. This is in agreement with a recent Australia wide survey (McInnis, James \& Hartley, 2000).

A small shift away from courses comprising all face to face student-teacher activities to courses with a mix of face to face and online activities has the potential to help those very students who may otherwise give up when the pressure of time and other commitments increases. It is also acknowledged that students have different study skills and therefore we need to use a 
variety of techniques to assist their learning, which must be embedded in the teaching and learning environment (Lewis, 1993). Changes that would allow a more flexible approach include: improved access to learning resources; provision of flexible student support systems including counselling services, bridging, catch up, remedial and study skills courses; and the development of learning resources and experiences that cater for different learning styles (Lewis, 1993). Computer learning resources delivered on the Web can fit these descriptors, but to be effective courseware must offer an opportunity for learners to address a topic through a range of activities appropriate to all learning styles (Valley, 1997).

Some of the recent moves in online presentation have been to develop Virtual Learning Environments (VLEs). Virtual learning environments can be described as online domains that permit synchronous, collaborative interaction among teachers and students, while also providing asynchronous learning resources for individual use by students at any time (Barajas \& Owen, 2000). VLEs thus offer a learning system made up of many components, with all the advantages of computer based learning but with the added advantages of access and use over the Internet. VLEs today include a plethora of alternative teaching spaces including Internet based courses, teleconferencing courses and virtual reality courses. The common link for all environments is that students come to a 'place' or use a technology to link them to a place to acquire new knowledge (Peat, 2000).

For the institution a VLE can offer a place where much of the essential learning for a course could occur, be encouraged, managed and monitored. For the students a VLE can offer a flexible, self paced, self centred learning experience that better suits the timetable of the students and their perceived learning needs (Palloff \& Pratt, 1999). Within the VLE students are able to view course materials, work on projects in small collaborative groups, engage in discussion, access reference materials, and communicate with their peers and teachers.

A VLE can be divided into working spaces (often as 'rooms' or 'laboratories') that are connected to each other by 'exits' or 'pathways' according to an intuitively spatial arrangement. This allows students to do the same things online as they can do in a face to face situation, e.g. students can meet in small discussion rooms; they can 'walk' to a virtual library; visit a resources centre; or visit their teacher's virtual office (by email) to ask a question. 
In First Year Biology at the University of Sydney a mix of on campus and online activities is used to create a better set of learning experiences for the students. Whilst the lectures are still very traditional in their delivery, students are encouraged to work collaboratively in peer groups during laboratory sessions, and either in groups or on their own when working online. Not only does this mix encourage the development of life long learning strategies but it is also sustainable in the current economic climate. The students are characterised by varied academic backgrounds (including a large range of incoming entry grades and some with no previous biology experience), with a varying interest in biology and with a range of generic skills. The student body has not changed in its characteristics over the last five years but it has grown in number from 1200 to 1600 . Teaching in first year biology involves repeat lecture series, multiple concurrent laboratory sessions, seemingly never ending reports to mark and vast numbers of examination papers to grade.

The sheer size of the operation can lead to impersonal interactions between the staff (dwindling in number) and the students (increasing in number). In 1990 there was one full time academic (identified as being a member of the first year team) per 100 students, whereas in 2000 there is one similarly identified full time academic per 163 students. The original development of an online resources room was discussed in Franklin \& Peat (1998a). The re-purposing of this resource into a virtual learning environment is documented in Peat (2000). This paper will discuss the mix of learning opportunities available to students taking first year biology units of study, describe the virtual learning environment, and assess the effect the virtual learning environment is having on the learning opportunities of the students.

\section{The mix of learning opportunities}

For more than ten years there has been a move within our first year units of study to change the philosophy from teaching students to facilitating student learning, especially within the laboratory experience. Early changes involved organisational and structural issues, such as the way the laboratory classes were designed or reviewing which activities best suited a student centred learning approach. Teaching methodologies and scenarios have been put in place that emphasise small group teaching and student centred learning, and facilitate the development of learning communities in class, all of which encourage peer assisted learning, communication skills and socialisation of the students (Franklin \& Peat, 1996). Delivering learning materials on computer, firstly within the 
laboratory class and then on the Internet, improved the access of students to the learning opportunities. With the development of a virtual learning environment on the Web we are now in a position to exploit best practice in web based delivery.

\section{On campus}

Our units of study are still campus based and students attend lectures and laboratory sessions in most weeks of the semester. There is a slight trend towards a reduction of the face to face delivery of these materials but in the light of strong departmental opposition to reducing the number of on campus lectures, this is a slow process. Laboratory sessions are a feature of experimental science disciplines and at least some of these sessions need to be retained. The introduction of computers in 1994 as a permanent feature in the laboratory and the development of computer assisted learning modules (CAL) to target specific learning difficulties led to a focus on the use of computers in the learning process. This in turn led to the development of an online resources room (Franklin \& Peat, 1998a), now re-purposed to provide a complete learning environment online.

\section{Online}

Since the early 1990s the use of computers in education has led to an explosion of material and delivery modes for teaching, learning, and assessment tasks. As a result of this we were able to offer the students a variety of computer based materials in our units of study, which with the development of the Internet were put online.

During 1999, feedback from student questionnaires, interviews and group discussions, as well as discussions with academic staff and the webmaster, indicated a perception that the original online resources room had become overcrowded and confusing, and that it had outlived its usefulness. It was perceived that there needed to be clearer separation of the functions, such as the separation of the learning resources from the communication facility, as well as the incorporation of additional functions. In particular there was a need to separate the functions of the communication facility to include asynchronous communication between students and staff on administrative matters and technical issues associated with the use of our materials over the Internet. These were seen to be issues best addressed by non-academic staff rather than academic staff, who currently were receiving all inquiries. In addition there was a need to offer students specific information about each unit of study to give a better sense of continuity and direction but without losing the functionality of the 
original online resource. This led to the development and launching of the Biology Virtual Learning Environment in semester 1, 2000.

\section{The Virtual Learning Environment}

The design of the VLE uses a building metaphor, the building representing the School of Biological Sciences. On completion of the VLE students will enter the foyer of the building and take the lift to any of Levels 1 to 3, representing the three years of undergraduate study. Currently our first year students $\log$ on directly to the VLE at the Level 1 Lobby (representing first year studies). Once in the First Year Lobby students are presented with access to general materials and help functions. Figure 1 shows the layout of the lobby [refer http://fybio.bio.usyd.edu.au/vle/L1/]. From the lobby the building metaphor is continued enabling students to enter various rooms, each of which represents a unit of study in first year biology, the Resource Centre (parts of the original online resources room) or other areas within the University, such as the University Library (Fisher Library catalogues).

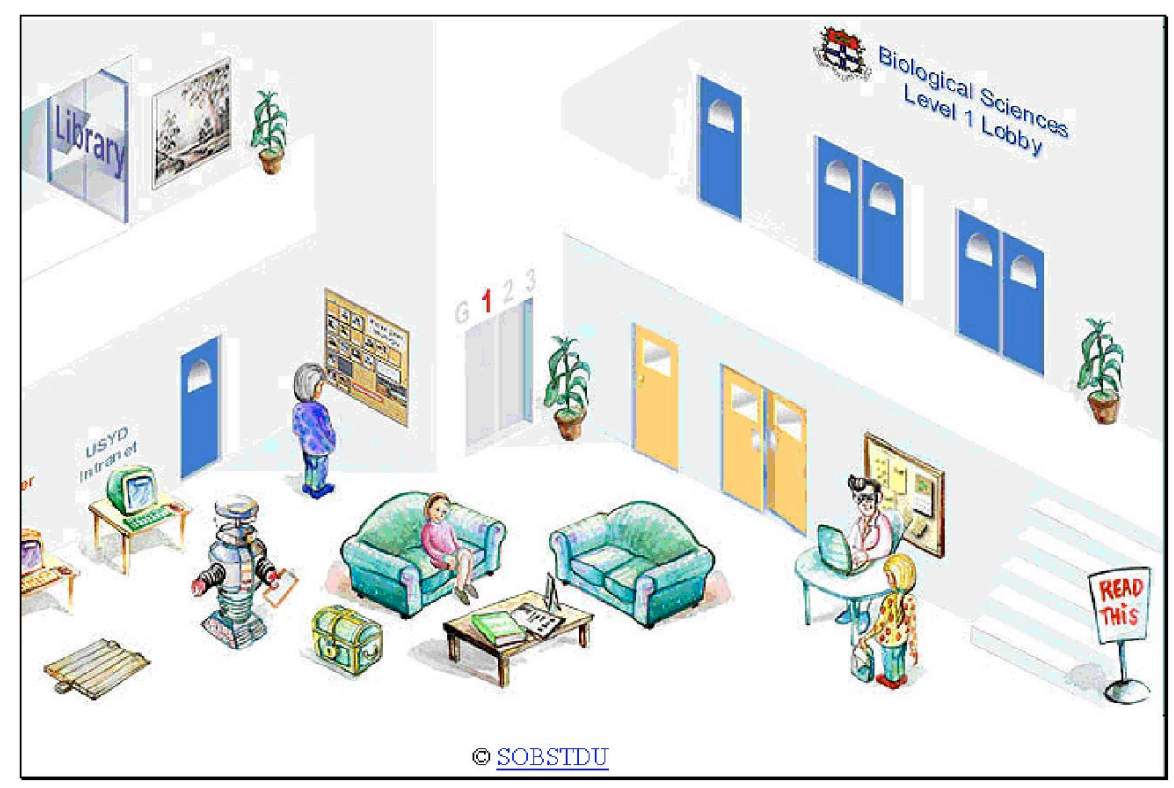

Figure 1: First Year Biology Lobby 
Within the lobby there is a notice board with the names and email addresses of staff, a coffee table with general information, and access to CyberAdmin and CyberTech, for answers to general questions of an administrative or technical nature. Importantly the lobby has doors opening into the separate units of study, with semester 1 units being on the same level as the lobby and the semester 2 units on the mezzanine floor. The Resource Centre contains all the computer based learning resources for all the units of study. All the icons/objects in the lobby and the unit of study rooms have "mouse over" pop up labels to assist with navigation.

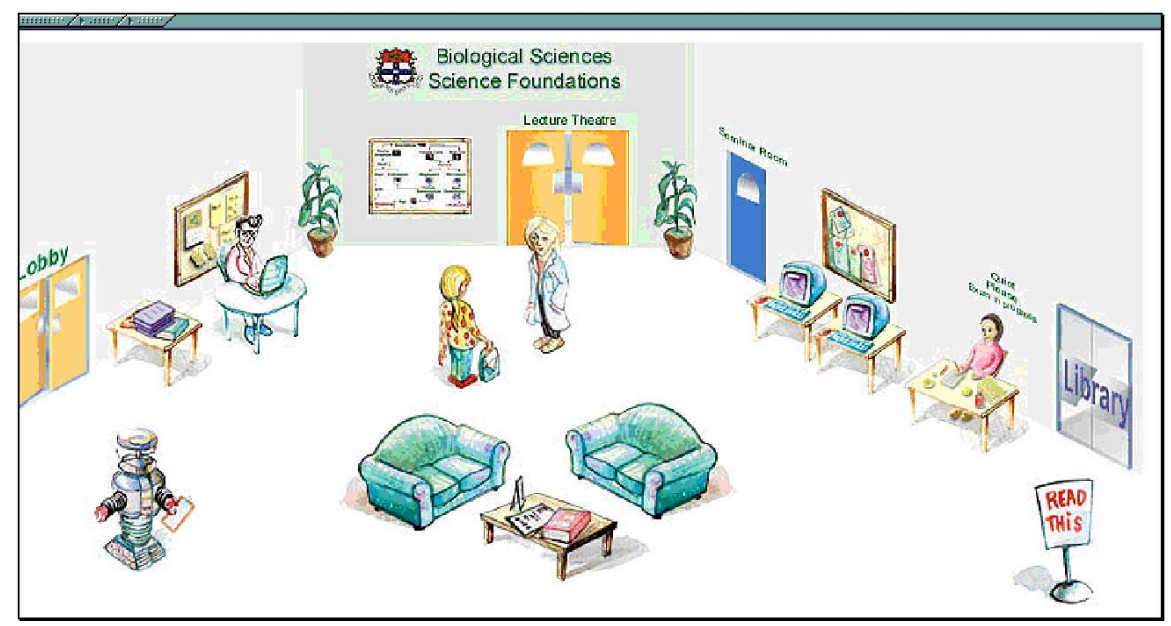

Figure 2: Unit of Study Room

The lobby leads students through a door into a unit of study. Once inside a unit of study room (see Figure 2) there are resources available that are appropriate for the unit and exits to areas such as the University Library and the Lobby, and doorways to the lecture theatres (lecture notes) and a seminar room (web based discussions). On the wall a notice board provides current information concerning that unit of study. CyberTutor appears here and is available to discuss biological content, while CyberAdmin and CyberTech are also available in the unit of study room. The development of CyberTutor was discussed previously (Franklin \& Peat, 1998a) and whilst Barnes (1999) emphasises the need for students to remain anonymous when communicating electronically with staff, we have not found that this lack of anonymity deters the students from contacting us: in fact the opposite may be true. Learning materials are 
available from computers (tutorials, revision modules, remedial materials and self assessment modules) and there is a desk where students can access tests and exams (answers to weekly self test questions from the lab notes and to a mid course exam and sample exam questions). In this way the students are directed to focus their attention on the materials, communication functions, and discussion forums that are available for the specific unit of study without being presented with all the materials available in the Resource Centre.

A discussion forum, specific to the unit of study, encourages students to access each other in real or virtual time, although it is best used asynchronously. It allows students to post questions or discuss any topic with their peers. A general biology discussion forum is also available via the lobby. Student use of this facility was slow initially but has increased as more students obtain better access to the Internet and their skills in using these facilities improve. Discussion topics include: exams; lectures; lab reports; ethics of using animal materials; posters; lecture theatres; how to reference URLs; and technical help with downloading materials. Future development will include staff mediated discussions. These are currently being trialed using WebTeach and have proved to be most successful, especially during periods of report writing and examination preparation.

\section{Evaluation of the use of the Virtual Learning Environment}

External peer reviews of the biology learning environment have been very positive (Jones, 1999; Fyfe, 1999). Jones (1999) stated that the site is an impressive product of a dedicated teaching group, who have whole heartedly embraced the versatility of online teaching and also indicated that the pedagogy had been carefully considered in the design of the site. Jones also highlighted comments made by students in the discussion forum (which gave insights into their experiences of the learning process) as an example of well designed electronic learning materials. Fyfe (1999) felt that the strengths of the site are the Self Assessment Modules, the CyberTutor facility and the discussion lists and was pleased to see the amount of course content discussion between students.

In April 2000 a survey was sent by email to 400 of 1300 students (all students are provided with a free email address by the University) regarding their access to computer resources, and their perceptions and usage of the VLE. The response rate was $25 \%$. It is appreciated that the results may be slightly biased towards students who take the trouble to 
use the email provided. Of those students $98 \%$ had used the VLE, 94\% were connected to the Internet at home but only $68 \%$ had loaded the required plug in Shockwave for Authorware on their machines. Of those student who had used the VLE all of them had accessed the lecture notes whilst less than $45 \%$ accessed other material such as computer based learning modules, self test answers etc. Use of modules is probably related to the requirement for Shockwave. Most students $(82 \%)$ found the site easy to navigate. This data can be compared to a 1999 paper based survey indicating $93 \%$ of students had used the online resources room with $81 \%$ accessing it from home.

Compared to previous years, $16 \%$ of students have found accessing our materials frustrating this year, as most of the CAL requires the plug-in Shockwave for Authorware, which has increased in complexity and download time, causing problems for students. To address this extensive download time we are providing CD-ROMs with Shockwave for students, to facilitate their access to our materials.

We have also come to realise that due to increased usage of the Internet in homes for business, pleasure, research for school projects and for access to the VLE, our students may be experiencing difficulties in their households competing with other users of the Internet and the available telephone lines. A recent survey indicates that $37 \%$ of students using the Internet at home report competition for its use. We will consider offering a CD-ROM next year with all the CAL modules, thus giving students better access to our learning resources whilst leaving the communications side of the VLE dependent on the Internet.

Analysis of CyberTutor usage indicates that the students are using the facility mainly for accessing information about academic matters (lectures and lab classes) and that queries about Internet use have begun to decrease (see Figure 3). This reflects the increased skill base of the incoming students and also the fact that we have made a greater effort to help our students develop the generic skills required. The total number of enquiries to staff via CyberTutor is still rather low and this needs to be investigated. However the student usage of face to face consultations is also declining, which may be a reflection of the increasing numbers of students in paid employment and the decline in on campus time available. 


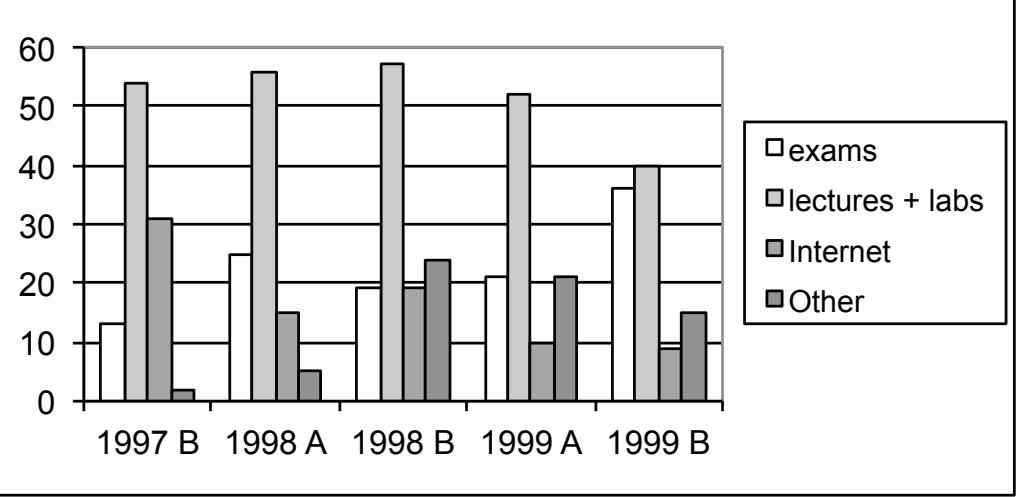

Figure 3: Email enquiries by category as a percentage of total enquiries.

"A" represents Semester 1 each year and "B" represents Semester 2.

\section{Discussion}

In Australia, as elsewhere in the world, most institutions in higher education are committing themselves to using computers in education. This is happening for four compelling reasons: the number of staff per student has decreased; the modularisation of courses is increasing the pressure to share materials; technology is beginning to offer stability to meet user expectation; and there is a consumer expectation that an institution will be heavily involved in information technology and computer assisted learning materials. In the science context there is a strong push to investigate alternatives, such as virtual dissections, experiments and field trips, to some face to face laboratory experiences.

The new technologies have the ability to provide greater flexibility to our students by providing learning environments that are accessible to individuals any time and any place, and, due to their capacity for interaction and feedback, cater for different learning styles. However, we see IT resources as an adjunct to human teachers, facilitating learning rather than teaching. First year biology aims to mix virtual learning on the Internet with "real" face to face learning in laboratory sessions and lectures, with an emphasis on accessing learning resources via the Internet. Our VLE is neither a substitute for nor a complete departure from, the traditional teaching environment, but a compelling extension of it. The challenge we face is to identify the best in VLE-type learning and use it in conjunction with traditional classroom teaching. 
We have used a mix of face to face activities and online activities to offer students a greater flexibility in the learning environment. Candy, Crebert \& O'Leary (1994) suggest that courses that enhance lifelong learning must offer some flexibility in structure and provide for development of self directed learning. In line with this we have changed our philosophy from teaching students to facilitating student learning, especially within the laboratory experience, with a move from teacher centred to student centred learning. The introduction and use of computers along with peer group learning communities in our large classes, and the effect this has on facilitating student learning, has been discussed elsewhere (Franklin \& Peat, 1998b).

Gibbs (1992) proposes that the appropriate focus of attention in improving the quality of student learning is course design and process rather than teaching and content: we support this. In addition, it has been argued (Fraser \& Deane, 1997) that students must engage in meaningful learning if they are to become suitably equipped for the workplace, with a knowledge base and understanding that is expandable and transferable in years to come. With these in mind, we initially created an online resources room to help students engage in meaningful learning, This led to the development of a Virtual Learning Environment in which we offer students opportunities to be involved in group or individual activities. Current research is targeting the overall fit, in our units of study, of the learning opportunities - lectures, independent study modules, lab classes, and revision and self help materials online, with an emphasis on the use of computer/web based materials.

The future for science teaching is to use the resources in the best possible mix for the discipline and one of the issues for the future will be how we assess the effectiveness of the mix of learning opportunities. Evaluation of the contribution of all components within a unit of study, and not just the computer/web based materials, is essential.

\section{References}

Barajas, M. \& Owen, M. (2000) Implementing virtual learning environments: Looking for holistic approach. Educational Technology and Society, 3 (3), 39-53. [verified 16 Mar 2001] http: / / ifets.massey.ac.nz/periodical/vol_3_2000/barajas.html

Barnes, D. J. (1999). Public forum help seeking: The impact of providing anonymity on student help seeking behaviour. Proceedings of Computer Based Learning in Science Conference, The Netherlands, July 1999. [viewed18 Aug 2000, verified 16 Mar 2001, abstract] http: / / www.cblis99.freeuk.com/abstract.htm\# A3 
Candy, P. C., Crebert, G. \& O'Leary, J. (1994). Developing Lifelong Learners Through Undergraduate Education. National Board of Employment, Education and Training, Australian Government Publishing Service.

Christopoulos, J. P., Rohwer,W. D. \& Thomas, J. W. (1987). Grade level differences in students' study activities as a function of course characteristics. Contemporary Educational Psychology, 12, 303-323.

Franklin, S. \& Peat, M. (1996). Mechanisms for facilitating group learning in first year biology: Assisting the transition. In R. James \& C. McInnis (Eds), The 2nd Pacific Rim Conference on the First Year Experience in Higher Education. The Centre for the Study of Higher Education, Melbourne (232-242).

Franklin, S. \& Peat, M. (1998a). Online Learning: the First Year Biology Way. In Proceedings of the 15th Annual Conference of the Australasian Society for Computers in Learning in Tertiary Education, December 1998. http: / / www.ascilite.org.au / conferences / wollongong98/asc98pdf/ franklinpeat.pdf [verified 16 Mar 2001]

Franklin, S. \& Peat, M. (1998b). Strategies to support learning and student progression: The first year biology way. In Proceedings of the Third Pacific Rim Conference - First Year in Higher Education: Strategies for Success in Transition Years, July, Auckland, New Zealand.

Fraser, S. \& Deane, E. (1997). Why Open Learning? Australian Universities Review, 40(1), 25-31. In: http:/ / www.nteu.org.au/services / publics / aur/aur197.pdf [verified 16 Mar 2001]

Fyfe, S. (1999). First Year Biology Virtual Resources room, School of Biological Sciences, the University of Sydney. [viewed 18 Aug 2000, verified 16 Mar 2001] http: / / science.uniserve.edu.au/disc/ reviews/vrr2.html

Gibbs, G. (1992). Improving the Quality of Student Learning Oxford Centre for Staff Development, Bristol Technical And Educational Services Ltd, Bristol.

Horgan, B. (1998). Transforming Higher Education Using Information Technology: First Steps. Microsoft in Higher Education, Jan 1998. http:/ / microsoft.com/education/hed/vision.html [viewed 18 Aug 2000, unknown 16 Mar 2001]

Jones, S. (1999). First Year Biology Virtual Resources Room. [viewed 18 Aug 2000, verified 16 Mar 2001] http: / / science.uniserve.edu.au/newsletter/vol13/jones.html

Lewis R. (1993). The progress of open learning. Education and Training, 35(4).

McInnis, C., James, R. \& McNaught, C. (1995). First Year on Campus: Diversity in the initial experiences of Australian undergraduates. A Commissioned Project of the Committee for the Advancement of University Teaching, September 1995. Centre for the Study of Higher Education, University of Melbourne. 
McInnis, C., James, R. \& Hartley, R. (2000). Trends in the First Year Experience in Australian Universities. A commissioned project for the Department of Education, Training and Youth Affairs, EIP Commonwealth of Australia. [verified 16 Mar 2001]

http:/ / www.detya.gov.au/archive/highered/eippubs/eip00_6fye.pdf

Palloff, R. M. \& Pratt, K. (1999) Building Learning Communities in Cyberspace. JosseyBass Publishers, San Francisco.

Peat, M. (2000). Towards First Year Biology online: a virtual learning environment. Educational Technology \& Society, 3(3), 203-207. [verified 16 Mar 2001] http: / / ifets.massey.ac.nz/periodical/vol_3_2000/b06.html

Peat, M. \& Franklin, S. (2000). 2000 - Survey of Demographics of First year Biology students, including casual hours worked in semester. http: / / fybio.bio.usyd.edu.au/SOBSFYB / fyb / tdg/AnnReports / Finals2K.htm [viewed 18Aug 2000, verified 16 Mar 2001]

Valley, K. (1997). Learning styles and courseware design. Association for Learning Technology Journal, 5(2), 42-51.

Sue Franklin, Biological Sciences

The University of Sydney, Australia

sue@bio.usyd.edu.au

Mary Peat, Biological Sciences

The University of Sydney, Australia

maryp@bio.usyd.edu.au 